\title{
Mot Hazkená (A Morte da Velha) - Conto de Yaacov Steinberg
}

\section{Mot Hazkená (The Death of the Old Woman) - Tale by Yaacov Steinberg}

Gabriel Steinberg*

\begin{abstract}
Resumo: Este texto apresenta a tradução do conto Mot Hazkená (A Morte da Velha), do escritor em língua hebraica Yaacov Steinberg. Steinberg foi um dos mais destacados escritores do período do renascimento do hebraico vernacular na Terra de Israel, país ao qual chegou em 1914, no final da segunda onda imigratória rumo à terra ancestral. O conto aqui apresentado descreve o fim de uma idosa, cuja vida de esvai de forma lenta e gradual.
\end{abstract}

Palavras-chave: Literatura judaica. Língua hebraica. Diáspora judaica.

\begin{abstract}
This text presents the translation of the short story Mot Hazkená (The Death of the Old Woman), by the Hebrew-language writer Yaacov Steinberg. Steinberg was one of the most outstanding writers of the period of the revival of vernacular Hebrew in the Land of Israel, where he arrived in 1914, at the end of the second wave of immigration towards the ancestral land. The tale presented here describes the end of an old woman, whose life slowly and gradually fades away.
\end{abstract}

Keywords: Jewish literature. Hebrew language. Jewish diaspora.

Yaacov Steinberg, é um dos grandes nomes da literatura hebraica da primeira metade do século XX. Ele nasceu em Bila Tserkva, região central da atual Ucrânia, que na época fazia parte do Império Russo (1887). Seu pai era açougueiro e ele iniciou seus estudos numa escola rabínica. Em 1901, aos 14 anos, abandonou a cidade natal chegando a Odessa ${ }^{1}$, na época um dos principais centros da intelectualidade judaica. Ali ele conheceu Haim Nachman Bialik e entrou em contato com a literatura hebraicas. Em 1903, passou de Odessa para Varsóvia onde conheceu o escritor I. L. Peretz. Em Varsóvia, ele começou a participar da imprensa escrevendo tanto em iídiche como em hebraico. Em 1910, mudou-se para a Suíça onde estudou na

\footnotetext{
* Gabriel Steinberg é professor no Departamento de Letras Orientais da Faculdade de Filosofia, Letras e Ciências Humanas da Universidade de São Paulo. E-mail: 〈steinberg1818@usp.br>.

${ }^{1}$ Odessa - Cidade portuária ucraniana às margens do Mar Negro. No século XIX era a terceira cidade mais importante do Império Russo atrás apenas de Moscou e São Petersburgo. Os judeus se estabeleceram na cidade no século XIX quando ela se tornou um porto livre. Calcula-se que a população judaica somava mais de 160 mil pessoas no final do século, o que a tornou a maior cidade de população judaica do Império. Os judeus da cidade sofreram vários pogroms em 1881 e 1905. No final do século XIX, consolidou-se na cidade o movimento do iluminismo judaico, e muitos judeus passaram a frequentar escolas e universidades e também foi fundada ali uma escola judaica moderna. Ainda nessa época foi criado um centro de apoio ao movimento sionista e Odessa se transformou numa importante base de atuação do movimento nacionalista judaico. Foi ali que atuaram alguns dos grandes escritores sionistas e pioneiros da moderna literatura hebraica, entre eles Bialik e Klausner.
} 
Universidade de Berna. Retornou a Varsóvia para escrever no jornal iídiche Der Fraynd, que foi o primeiro jornal em iídiche a circular diariamente no Império Russo entre 1903 e 1912. Em 1914, Steinberg chegou à Terra de Israel já no final da segunda aliyá, a segunda onda imigratória para a terra ancestral e, desde então, passou a escrever apenas em hebraico. Faleceu na cidade de Tel Aviv em 22 de junho de 1947.

O conto aqui apresentado é uma tradução diretamente do hebraico. Mot Hazkená (A Morte da Velha) descreve o cotidiano de um jovem que, vivendo na casa de seus avós, deve enfrentar a morte da idosa, mãe de sua avó Chaya. A morte que é uma etapa da vida é marcada no conto com uma narrativa atemorizadora. A vida da idosa, personagem central da narrativa, se esvai de forma lenta e gradual.

\section{Mot Hazkená (A Morte da Velha) ${ }^{2}$}

Na hora do retorno da sinagoga, Yossile costumava andar ao lado do avô, e por causa do frio ele batia na terra com suas pesadas botas tentando se desfazer um pouco da neve que as cobria. Ao ingressar no corredor da casa, lugar onde o frio parecia ser ainda mais intenso do que fora, e onde imperava a escuridão da noite de Shabat, o menino permanecia em pé, apreensivo, aguardando o avô, vendo-o fechar a porta com uma vara de madeira, enquanto o mesmo também procurava dissipar a neve que cobria seus sapatos apoiando-se num barril de água coberto de gelo. Naquela noite, Yossile estava ainda parado perto da entrada da casa, quando foi tomado por um tremor. Então ele foi atrás do velho, caminhando a passos contidos ao longo da cozinha, lugar no qual podia ser vista a luz agonizante da uma vela. Depois era preciso passar pelo corredor estreito que se encontrava em frente à sala de jantar, onde podia ser sentido o calor agradável vindo do forno que ali estava aceso. Nesse momento, o menino conteve o passo atrás de seu avô, mas sentiu-se apreensivo, quando pode vislumbrar, como nas outras vésperas de sábado, as camas já arrumadas para uma noite de sono. Todos os dias da semana ele ia se deitar somente depois de sentir o corpo congelar de frio dentro da loja de seu avô, já que era ali que ele ficava todas as noites até a hora do fechamento do comércio. Mas na noite de Shabbat tudo era diferente.

Yossile costumava proferir a saudação de paz, o Shabbat Shalom, antes mesmo que seu avô. E para isso ele pronunciava as palavras com entusiasmo e com o coração leve, observando

\footnotetext{
2 STEINBERG, Yaacov. Mot Hazkená. Project Ben Yehuda. Disponível em: <https://benyehuda.org/print/10310>. Acesso em 11/07/2018.
} 
nesse momento as velas acesas sobre a mesa, consumidas já pela metade, e somente a expressão Shabbat Tová, um bom sábado, pronunciada pelo ancião, expressava um cansado anelo de paz pronunciado por um judeu simples, e engolida pelas dobras do lenço de lã que ele tirava do pescoço a fim de conter os gemidos provocados pela tosse. Nesse momento, a avó Chaya respondia a ambos, escutava-se então sua voz cansada ou como se tivesse mudado de entonação por algum motivo. E quando ela se levantava de seu assento por um instante, mesmo que sem uma prévia intenção, ela passava os dedos sobre a garrafa cheia de vinho até a metade, como uma pessoa que se lembrara de alguma coisa sem saber ao certo o quê, mas a seguir, ela voltava imediatamente para se sentar em seu lugar, pronunciando novamente: "Shabbat Tová, Shaná Tová”, e desta vez sua voz era ouvida de forma clara.

Nesse momento ela olhava para o rosto de sua mãe, colocando a mão sobre a testa, para poder ver o rosto da velha deitada sobre um travesseiro. Mas a idosa mãe, exausta pela idade avançada, permanecia deitada em sua cama durante todo o dia, respondia à filha e à bênção do sábado, uma resposta completa e mais um adendo: "Um bom sábado, um sábado bom para você!". E diante dessa voz afável, algo incomum se espalhava pela casa. Mas depois de um instante, a velha virava-se na cama e ouvia-se um gemido de resmungo:

- Estou sentindo frio - a porta, a porta!

Todos os dias aquela velha resmungava. A avó Chaya conversava com ela sempre, no entanto, aquele montículo vivo de ossos respondia após um prolongado bocejo, semelhante aos bocejos que as senhoras idosas dão nas noites do sábado, acostumadas a expressar todo o prazer de seus sábados e de suas vidas, concluindo depois com um breve e curto suspiro. Imediatamente depois, tentam se desvencilhar do prazeroso bocejo do sábado, tal qual uma pessoa que depois de comer um alimento doce, sente um sabor amargo na boca. Então, a avó Chaya dizia ao esposo naquele momento, enquanto se encolhia por baixo de seu lenço:

- É hora de fazer a bênção?

Yossile que tinha abandonado a casa de seu rabino e mestre no meio daquele verão, folheava o livro de orações da avó, recitando as melodias de Shabbat numa leve censura à avó, enquanto aguardava a chegada dos agradáveis momentos na hora da melodia Shalom Aleichem, e ainda assim ele não conseguia evitar de sentir prazer, enquanto contabilizava as rimas tal qual uma criança temerosa do Divino. Enquanto isso, o avô também se somava com sua voz rouca à voz do menino cantando, mas logo se calava caminhando silenciosamente de um canto da sala para o outro. Essa caminhada de um canto a outro, é o mesmo andar que todo judeu experimenta nas noites de Shabbat, enquanto observa com um piscar de olhos o par de velas 
que espalham luz e paz envolta da mesa. O regozijo repentinamente se esvaia, mas o avô permanecia em pé ao lado da mesa, olhando a chama das velas com os olhos congelados, semelhantes a um homem que não tem paz de espírito até que seu olhar finalmente se fixava na ponta dos seus dedos a segurar as escamas dos peixes salgados que brilhavam. Por um instante ele ocupava a mente em se desvencilhar dos restos de poeira que se acumulavam sob suas unhas, mas logo depois ele virava a cabeça para um lado, e no meio de uma expressão que continha um quê de tristeza, ficava admirado como os demais moradores da casa com as palavras contidas que a velha pronunciava enquanto virava o rosto para a parede:

- Mais uma vez estou sentindo frio - se ao menos eles já estivessem sentados à mesa... à mesa....

Suas palavras podiam ser compreendidas como murmúrios ou apenas queixas, algo comum numa velha, mas a avó Chaya pronunciava palavras de reprovação, pois sentia que esses murmúrios tinham a intenção de atingi-la com palavras duras, palavras que emitidas a fim de ferir. E o avô já estava habituado com esses conflitos, chegando a sentir um certo conforto no coração. E então, ele esfregava com prazer as pontas dos dedos endireitando-os de forma intencional e apontando em direção ao leito da velha. Mas após isso, o ambiente de Shabbat voltava a reinar na casa. Depois do avô, chegava a vez de Yossile de fazer a benção do vinho, e sua voz clara ecoava a título de conciliação na vida dos velhos. Depois disso, Yossile separava uma fatia da chalá, e, a mando de seu avô, a estendia em direção à velha. Então a fatia de pão se desmanchava em suas mãos tal como acontece com as tenras crianças, mas ao sentir o contato dos dedos pequenos e marrons que apareciam repentinamente por baixo do cobertor da idosa, toda a ternura infantil se esvaia, e Yossile voltava a sentar-se à mesa levemente envergonhado e assustado, e ele permanecia cabisbaixo, com a cabeça reclinada sobre o prato no qual tinha sido servida sua porção de peixe. E no canto do prato seu avô lhe colocava ainda uma macia fatia de chalá, cuja casca escura chamava a atenção do jovem.

Naquele sábado, na hora da refeição, a sala foi dominada pelo silêncio. Tanto Yossile como sua avó que tinha saído para a cozinha, já haviam terminado de comer o peixe, somente a velha, deitada em sua cama, continuou a saborear as espinhas ainda presentes no prato, e o velho avô ainda se deliciou comendo o que tinha restado da cabeça do peixe. Enquanto isso, a gata preta, que vivia na casa por anos, deitou-se no chão após ter saltando de seu lugar habitual perto do fogão quente. Apenas a velha escutou o som do salto, quando, repentinamente, uma fina espinha do peixe escapou e caiu ao chão. A gata se esticou ao lado da cama, fixou os olhos amarelos no rosto da velha, e ambas olharam uma para a outra, não em busca de compreensão, mas apenas como às vezes os olhares das crianças se encontram, num misto de distanciamento 
e aproximação. E a velha, como se quisesse recuperar o objeto perdido, repentinamente jogou uma espinha com a intenção de afugentar a gata e logo resmungou:

- Saia! Não tenho forças para aguentar isto.

A vovó Chaya, que acabara de chegar com o caldeirão nas mãos, sentiu-se compelida a provocar a mãe:

- Novamente com a gata?

A seguir ela serviu à idosa um pouco de sopa numa tigela pequena e funda. Então, como de costume, logo, a colher do avô começou a soar ao bater na tigela e ao sacudir a barba. $\mathrm{O}$ velho olhou para a esposa, cujos olhos estavam momentaneamente sonolentos. Os olhos do vovô pareciam brilhar, como se ele não tivesse ficado ainda satisfeito com a refeição, ou como se quisesse dizer alguma coisa à esposa, mas ela permaneceu em silêncio, sem ouvi-lo. De repente, a vovó Chaya começou a gritar:

- Ai, ai, ai - gemendo uma e outra vez. Suas mãos estavam estendidas sobre o peito e apenas um olho permanecia ainda aberto. Yossile apressou-se para acudi-la:

- Vovó! Vovó! - a velha avó começou a sacudir-se naquele momento para tentar mostrar que nada tinha acontecido, ao que Yossile disse em voz baixa, mas sem pensar:

- Esta é a noite de Shabbat, um Shabbat bem diferente de qualquer outro.

Ao perceber o que dissera, Yossile ficou calado e envergonhado, e o avô desistiu de falar alguma coisa, como se a fala do rapaz tivesse aliviado o pensamento que perturbara o velho. E, logo após, ele começou a cantarolar as canções alusivas ao Shabbat, instando Yossile a acompanhá-lo com as melodias, porém esse não se apressou em partilhar sua voz para entoar as difíceis canções, com cuja letra o próprio avô se confundia. Mas dessa vez, porém, o avô não se esquivou de uma reflexão silenciosa no intervalo em que era servida a sopa e depois a carne, tal qual ocorria todo dia de Shabbat à noite nas humildes casas dos judeus, casas nas quais a vida parecia estática. $\mathrm{O}$ avô também sacudiu sua barba com um gesto de impaciência, e exigiu que sua esposa terminasse de servir a refeição:

- Sirva a carne - ele lhe disse.

E como numa espécie de eco, ouviu-se repentinamente uma fala em tom de sussurro:

- Chayale, sirva a carne.

Todos sentaram-se imóveis ao redor da mesa, seus corações estavam apreensivos como os corações das pessoas prestes a chorar, e Yossile fixou seus olhos por um longo tempo na cama da velha. O rapaz estava ciente de que algo que não lhe era familiar iria acontecer na casa num curto intervalo, tão curto quanto o limite entre um instante e outro. Nesse momento Yossile 
ficou de pé brincando com nozes com seus amigos, aproveitando entusiasmado o jogo, jogo esse que ocorrera pela última vez na festa de Sucot. Naquele dia o avô o convocou a participar da oração da tarde, mas Yossile ficou imóvel e continuou a participar do jogo, negando-se a atender o pedido do avô, e recusando-se como é típico entre os jovens disse:

- Estou brincando com as nozes!

Mas após pronunciar essas palavras, Yossile ficou envergonhado com o que dissera, sua mão permaneceu fechada e ele não arremeteu o par de nozes como tinha planejado fazer até aquele momento. Ele quis chorar de tanta vergonha que sentiu, mas nesse momento tomou a decisão de que nunca mais iria dizer tais coisas ao seu avô, e então ele saiu atrás do velho. Desde aquele dia, Yossile soube, em seu íntimo, que às vezes palavras são pronunciadas naquele teor e, no entanto, reconhecer o erro não alivia os pensamentos que afligem os jovens. Por isso Yossile procurou compreender a feição do rosto do avô, mas ele não conseguiu entender o que esse rosto lhe sinalizava, e no entanto, the pareceu que havia algo no olhar do avô, pois esse lhe arremessou alguns pedaços de carne e lhe disse num leve tom de reprimenda, fato que pareceu ao jovem como uma ordem:

- Coma!

Nesse momento, as mãos da avó Chaya estavam tremendo enquanto ela colocava alguns pedaços de carne dentro do prato para sua velha mãe.

Mas depois disso, quando os ânimos pareceram mais calmos, foi servida a compota de ameixas enquanto todos se deleitavam comendo algumas frutas sem que a velha tivesse recebido esses alimentos. A idosa cobriu o rosto com uma almofada escondendo-se e permanecendo assim fora da vista de todos.

Quando a velha estava deitada, eles costumavam não insistir para que ela comesse toda a comida. Mesmo quando a comida era trazida e uma bacia batia na outra, o avô esfregava as mãos enquanto as lavava na água. Enquanto pronunciava a bênção de Shabbat, lhe pareceu por um momento, que ele poderia estar sentindo o prazer do paraíso se estivesse esticado nesse momento na cama debaixo de seu edredom de penas.

Então Yossile pronunciou uma bênção tão agradável e suave que o avô parou no meio, afastou-se do jovem, mas em seguida encontrou o verso no qual ele parara, interrompeu o jovem, mas logo forçou o garoto a prosseguir, e esse, envergonhado, apressou-se para recitar a Bircat hamazon, a bênção dos alimentos. Mas ao recitar a bênção "O Misericordioso", repentinamente o avô repetiu as mesmas palavras, pronunciando-as repetidas vezes: - "o Compassivo, o Misericordioso". E o avô concluiu a oração "o Misericordioso" e ao pôr fim à bênção de Bircat hamazon, juntamente com o neto começou a arrumar as cadeiras para uma 
noite de sono. Nesse momento, a vovó Chaya trouxe um travesseiro para o menino enquanto ela bocejava antes de dormir. $\mathrm{O}$ avô começou a fechar as portas, mas como ele fazia todas as noites, também dessa vez as deixou entreabertas. A vovó Chaya foi novamente até a sala para se certificar de que o jovem já tinha se deitado. Ela aproveitou e levantou as beiradas da toalha que cobria a mesa, pois essa toalha servia como um biombo entre o garoto e a parede. Depois disso, ela colocou o cobertor protegendo bem os pés do menino. O silêncio se abateu repentinamente sobre a casa. Nesse momento, a avó inclinou-se sobre a cama, mas Yossile desviou o olhar parecendo observar as velas que ainda haveriam de ficar acessas por um longo tempo.

Assim como as pessoas fazem antes de dormir, Yossile também se deixou levar pela imaginação. Foi então que a luz do par de velas que ainda iriam arder por um longo espaço de tempo, apareceu na sua frente. As chamas se assemelhavam a duas línguas de luz alongadas parecendo conciliar-se uma na outra até se tornar um único filete alongado. Ao jovem, o brilho das velas parecia flutuar e deslizar sobre uma superfície cintilante, agitado e espalhando-se em várias direções.

Tão pálida era a pele de Yossile, que ele parecia não sentir o brilho, mas em poucos instantes a luz que o rodeava iria se extinguir naquele vazio como a água que corre e desaparece. Yossile pareceu flutuar, seus olhos estavam fechados sem conseguir enxergar, seu coração silenciou e um círculo de luz apareceu diante dos seus olhos fechados, seu corpo estremeceu. O corpo do menino ficara imóvel e suas mãos estavam colocadas sobre os joelhos, a porta da rua já fora trancada, e todos naquela casa já encontravam-se deitados prestes a pegar no sono. Apenas Yossile não dormia ainda, ele estava dominado pela ansiedade. Repentinamente sentiu um toque e seus cílios se elevaram num leve tremor fazendo com que acordasse daquela doce letargia que o tinha dominado.

O menino abriu os olhos, enquanto seu corpo estava entorpecido e suas mãos ainda apoiadas sobre os joelhos. Foi então que ele olhou em direção à cama da velha. Yossile ficou intrigado, mas lamentou, no entanto, não ter podido perceber se a mulher estava de olhos abertos ou fechados. Imediatamente ele se virou de um lado a outro e seu corpo estremeceu levemente, mas como de costume, ele se deitou tomado por pensamentos, esperando que o sono o dominasse. Mas os pensamentos não o abandonavam e repentinamente ele se lembrou do poço d'água na área do mercado, o mesmo poço no qual todo balde acabava batendo na pedra antes de ser devolvido à superfície sem água. Yossile deduz então que o poço vazio era um sinal que 
o torturava à noite sem deixá-lo dormir, era o sinal que o fazia tropeçar em algo difícil e doloroso. E virando-se na cama de um lado a outro, o menino sentiu-se, pela primeira vez, apreensivo. Percebeu que se encontrava sozinho diante do mal cada vez mais próximo. Mas como fazem todas as crianças ao estender a mão para alcançar um objeto, o menino estendeu as duas mãos em direção à velha. Com os punhos fechados e os olhos arregalados, ele observou aquele rosto iluminado pela luz das velas. Então viu ali uma imagem assustadora. Temeroso, o menino retrocedeu levemente pois aquele rosto lhe pareceu como uma folha de árvore esmaecida pelo sol. Como todas as crianças, ele desejou ir correndo para perto de sua mãe ou de qualquer pessoa que pudesse acudi-lo com ternura, pois após observar o rosto da velha por um longo tempo, ele não desejava ser dominado por aquela imagem assustadora. Seus lábios sussurraram de forma curta e direta: "Não é possível, não é possível!".

De repente, após aquele sussurro, Yossile sentiu uma leve fraqueza, então ele permaneceu deitado na cama, angustiado, com o rosto coberto pelas mãos, consciente de sua solidão naqueles instantes de apreensão. Com os dedos entrelaçados, o menino voltou a olhar para a cama onde estava deitada a velha, ele percebe a iminente catástrofe, ele viu que os olhos negros da idosa não estavam fechados em sinal de descanso, mas também não estavam amplamente abertos pelo sopro da vida. Yossile permaneceu assim por longo tempo, dominado por uma profunda tristeza e apreensão. Nesse momento lhe pareceu como se a tristeza da infância e a angústia humana estivessem misturadas em sua alma. Ele permaneceu deitado de costas, enquanto refletia sobre a imagem que tinha visto.

Pela primeira vez na vida, ele começou a atentar para os mistérios do mundo que sobressaem do silêncio, ele prestou atenção à quietude, enquanto estava deitado com as mãos sob seu pescoço, parecendo um adulto que se deixara vencer pela insônia, seus olhos visivelmente claros, seu olhar era penetrante, então Yossile começou a entender que existiam mistérios na vida, e ele, um menino, estava sozinho neste mundo.

Yossile se sentiu solitário na imensidão do mundo, uma sensação de estranhamento com a grandeza do universo que pressionava seu coração. Seus pais pareceram-lhe distantes, a uma distância inimaginável. O som das batidas do relógio também lhe causaram temor, e só o rosto enrugado da velha estava próximo dele. Aquela velha de muita idade estava deitada, e ele sabia que o perigo e o medo o espreitavam. Ele se sentiu como um homem que teme a escuridão e tenta manter a luz que se exaure num quarto vazio. Como se tentasse se esconder dos temores que o afligiam, encolheu-se sob as cobertas que ele ergueu, e então lançou um olhar furtivo em direção à cama da velha. Olhou lentamente para cima, para o beliche encostado à porta daquele quarto, e com a respiração presa, caminhou cuidadosamente seguindo aquele beliche inteiro. 
Ele estendeu o olhar em direção à velha, até que repentinamente, dominado novamente pelo medo, soltou um grito que estava preso em sua alma. Sua cabeça girou como se tivesse caído dentro de um poço. Mas então ele se deitou novamente, permanecendo de olhos bem abertos, imóvel. Ele deteve o olhar demoradamente na cama da velha, quando lhe pareceu que a parede sobre a qual a cama da idosa se apoiava, tivesse se movido a uma boa distância, até um lugar onde sua visão já não podia alcançar. A parede ficou muito longe e o menino sentiu que ele fora introduzido num mundo dominado pelo silêncio. De repente o espaço que se abriu com o afastamento da parede não limitava mais seu olhar e, apesar disso, ele não conseguiu ver nada. No entanto, isso lhe causou uma angústia ilimitada, uma sensação estranha, pois em seu entorno tudo estava aberto, sem um limite para aquela imensidão. Dominado pelo medo e com a respiração ofegante, Yossile se sacodiu, sentou-se na cama, tirou o cobertor com um movimento rápido e com um forte impulso pulou para o chão.

Yossile caiu da cama sem saber o que estava acontecendo com ele e andou sem se incomodar com o frio que cobria seus pés. Andou novamente em direção à cama da velha, e a cada passo que dava, sua memória evocava inúmeras recordações. Essas recordações se intercalavam em sua mente de modo muito rápido, com a velocidade da respiração. $\mathrm{O}$ frio intenso que cobria seus pés logo espalhou-se pelo corpo, e quando estava prestes a dar os últimos passos em direção à cama da velha, pareceu assemelhar-se a uma criança cujo corpo tremendo desperta piedade. Dominado pelo cansaço e pelo medo, Yossile observou o rosto extenuado e pálido da velha iluminado pelas últimas faíscas das velas ainda acessas. O menino observou imóvel o rosto emaciado, então voltou para a cama, e foi vencido pelo cansaço. Em poucos instantes Yossile já estava dormindo, a mente dominada por sonhos e pela paz.

\section{C}

Quando o silêncio tomou conta da casa, o avô se preparava para dormir. Seu coração estava ligeiramente aliviado ao final de mais um dia. E quando já estava na cama, virou-se de lado tal como fazem as pessoas idosas, colocando as mãos sobre os ossos do quadril, sem sentir necessidade de olhar para sua esposa, que a essa altura já estava roncando sob as cobertas. As pálpebras do avô não piscavam diante da luz fraca vinda do outro quarto, e seu olhar permaneceu imóvel sem se prender a nada. Seus olhos, ao igual que os olhos dos velhos quando se retiram para o sono, brilhavam. Os pensamentos a respeito dos eventos desse dia iluminavam sua alma, mas ele não se mostrava preocupado com o dia seguinte, pois cada dia deve ser vivido independentemente do dia anterior, pois somente para os jovens, a vida se assemelha a um emaranhado de fios multicoloridos que rodam sem cessar. 
E assim o avô ficou sem se mexer, seu olhar imóvel, ele não se moveu por alguns instantes, somente mais tarde, tocou sua barba macia repentinamente, numa espécie de manifestação de prazer. Em seguida, imaginou estar vendo a loja no momento do fechamento após mais um dia de trabalho, e também imaginou ver o rosto aflito e curioso de Yossile ao examinar o cadeado da loja. Ele viu então o mercado e as estradas que dele partiam cobertas de neve que já endurecera pela passagem das charretes, e também se viu, segurando as chaves do comércio escondidas dentro da manga aquecida do seu casaco. Todas essas visões lhe apareceram juntas, mas em seguida elas desapareceram de forma conjunta, tal como uma chama que se apaga de forma repentina, e ele permanece ali visivelmente constrangido e tomado pelos pensamentos. Após alguns instantes, o avô foi vencido pelo sono e sua mente se tornou vazia. Mas, de repente, como num sussurro secreto, um pequeno lampejo de preocupação passou por sua mente.

Esta preocupação não foi motivada por um pensamento, esta preocupação era devida à inquietude que uma pessoa sente à vista de qualquer pequena alteração repentina. Mas no coração do avô, embora ele ainda estivesse quieto, ocorreu uma mudança silenciosa. $\mathrm{O}$ avô percebeu que alguma coisa estava prestes a acontecer, suas mãos estavam apoiadas sobre os ossos do quadril, e mesmo coberto, não sentiu o calor produzido pelo edredom. Ele quis pegar um outro edredom pesado, mas depois gemeu tal como os idosos inadvertidamente fazem, seus olhos começaram a piscar à luz bem fraca vinda do outro quarto.

Os olhos do avô procuraram pela luz tímida, e seu olhar ficou mais nítido. O avô não era vítima da insônia, mas o pensamento e a preocupação lhe provocaram irritação. E com essa ligeira irritação, ele entrecruzou as pernas uma na outra, e nas rugas da sua testa começaram a aparecer gotículas de suor, e seu coração foi tomado por uma estranha preocupação. Ele tentou encontrar alguma coisa que fora perdida. Embora o corpo do avô já tomado pelo envelhecimento foi rapidamente vencido pelo árduo trabalho, seus olhos ainda brilhavam cintilantemente, mas nesse momento seu olhar pareceu perdido no vazio.

E após alguns instantes de reflexão, ele percebeu que no outro quarto havia algo que requeria sua presença. Ele fechou os olhos de forma apressada. Seu coração bateu como em uma criança antes de chorar, e com amargura, começou a agitar os dentes. Movido por uma angústia estranha que diminuiu imediatamente quando ele pôs a mão sobre o rosto e enfiou os dedos em sua barba. E de repente, o corpo do avô tremeu ao ouvir o rangido da cama sob o corpo de sua esposa, que nesse instante começou a se virar de um lado para o outro. O corpo do avô continuou tremendo, seu rosto estava ainda enfiado na almofada, e apenas sua barba estava virada para a cama da esposa, cuja cabeça e pescoço ficaram descobertos. E o avô não 
pode desviar seu olhar para longe, observando o pescoço descoberto de Chaya, pescoço este coberto por tendões azulados proeminentes, então de seus lábios escutou-se um sussurro: "Mestre do Universo...".

E logo que sussurrou estas palavras, permaneceu deitado imóvel, dominado pelo medo, tal como alguém que foi condenado à morte espera pela chegada do verdugo. $\mathrm{O}$ avô jazia impotente, todos seus sentidos estavam imóveis, e apenas seus olhos se viraram em direção à a luz fraca vinda do outro quarto. Seus pés apareceram projetando-se para fora do edredom, e seus joelhos começaram repentinamente a se entrechocar. $\mathrm{O}$ velho sentiu que não conseguia esticar as pernas. Estava claro que ele próprio estava doente. O avô sacodiu lentamente os dedos das mãos que nesse instante estavam apoiados sobre seu coração, e esse leve choque deu origem a um momento de dúvida. Ele escutou as batidas do relógio vindas do outro quarto, e essas batidas pareceram-lhe vindas de algum lugar bem distante. Ele percebeu então que não era uma doença que tomara conta de seu ser, de seu corpo, e tal como uma criança assustada que começa a chorar, seu rosto coberto por incontáveis rugas, foi dominado pelo medo. A calamidade que estava para se abater naquela casa, não foi compreendida por ele, e assim ele não podia aceitála. Repentinamente o avô sentou-se em sua cama ao imaginar ouvir os passos de seu neto vindos do outro quarto, passos que deixaram de ser ouvidos depois de um breve instante.

$\mathrm{O}$ avô desceu da cama, embora estivesse incomodado com o frio da noite. Ele desejava ver o que teria motivado seu neto a acordar a essa hora avançada da noite, e para isso ele só tinha que virar sua cabeça para o outro quarto, enquanto segurava uma das duas portas. Então o avô esticou a cabeça por um momento em direção ao quarto, temeroso em ver a velha deitada com os olhos abertos. $\mathrm{O}$ avô olhou para a cama do menino e depois, por um instante, procurou pelo rosto da idosa. O rosto esquálido da velha permanecia fundo no travesseiro, então o avô voltou gemendo para sua cama. E quando fechou os olhos para voltar a dormir, olhou para a esposa por um momento, e percebeu que esta se encontrava num sono profundo e coberta com uma colcha até o pescoço.

Os dias se sucederam e a velha continuava deitada na cama, seguindo sempre a mesma rotina. Assim, após engolir o último fiapo de carne, ela baixou a cabeça deitando-a novamente no travesseiro. Sua mente parecia estar vazia e qualquer tentativa de se conectar com o mundo, estava fadada ao fracasso. Mas nem sempre o que parece ser é o que é na verdade e repentinamente a velha foi envolta por um sonho. Nesse sonho a sua mente foi tomada pela melodia de Birkat hamazon, a benção dos alimentos e os passos que eram ouvidos pela casa, 
pareceram repercutir em sua mente. Depois disso, quando o silêncio voltou a reinar em todos os cantos, a velha permaneceu deitada de olhos abertos e melodias pareceram vagar através do silêncio de sua mente. $\mathrm{O}$ sono da idosa vagueava como uma nuvem escura no horizonte mas, de repente, como que em meio a uma ruína situada ao longe, apareceu ali alguém à meia-noite carregando uma tocha. Nesse momento pareceu como se todos os compartimentos do corpo esquálido tivessem sido iluminados de repente e o som de um rugido a tivesse invadido. Uma mão invisível carregava a tocha de um lugar a outro, parecia à idosa que muitas coisas velhas e novas desfilavam à sua frente. Aquela luz parecia invadir todos os cantos e recantos da sua alma. Enquanto todos os espaços da casa estavam na escuridão, apenas aquele canto parecia iluminado por uma luz brilhante. A velha parecia ver tão bem, parecia olhar melhor para as trevas do que para a luz, parecia enxergar ao longe, atrás de recordações que lhe pertenceram e já se desconectaram de sua memória. A luz começou a tremular conforme a imagem invisível andava segurando a tocha, então o coração da velha se esvaiu não por causa de sua dor, mas pelas memórias e pela tristeza das recordações de sua vida. As recordações da velha se assemelhavam a uma árvore já idosa cujo tronco foi comido por pequenos animais deixando oco seu interior.

Nesse momento, a memória da idosa evocava a lembrança de sua filha, a imagem da avó Chaya, e essa imagem a perseguiu desde a manhã até o anoitecer. A imagem da filha se elevou diante da velha, e assim como o temperamento de uma pessoa muda na frente de uma encruzilhada, a irritabilidade da velha também se transformou num sentimento de pena, semelhante ao choro das crianças que termina com um suspiro antes de adormecerem. Agora a velha ansiava por sua filha. $O$ desejo de recapitular a vida estava lentamente se entrelaçando ao sentimento de amor, ela ansiou por trazer de volta a vida que foi separada dos tempos antigos, assim como os segredos que dominam a vida.

O tempo de tristeza sombria da idade tomou seus pensamentos e seus olhos permaneceram bem abertos para ver toda a luz do início de sua vida. Ela viu os anos da infância passando à sua frente como doce melodia. Enquanto os anos de juventude permaneceram estáticos diante dela. A velha se viu encostada a uma janela observando uma rua. A imagem da rua estava silenciosa, já que era um sábado de manhã, e as imagens invadiram a mente da idosa, eram as últimas recordações do início de sua infância, ela permaneceu apoiada à porta na expectativa do que estava prestes a vir. Ela parecia olhar, seu olhar era imóvel ao ver a rua na qual viveram seus pais, pela qual eles retornavam da sinagoga. Ainda, pela mesma janela ela viu passar muitas pessoas que lhe pareceram ser as sombras de árvores distantes, como se todas elas fizessem parte de um mesmo tronco. As sombras se aproximaram dela ainda mais até que 
pareceram encostar na própria janela, e ela ficou ali, observando e aguardando. Seu coração foi tomado pela dor. E de repente seu coração começou a bater muito rápido, e não era pelo sopro da vida que ele batia, mas sim devido a alguém que apareceu do lado de fora da janela.

Lá, para além da janela, havia uma imagem sem figura, não possuía sombra nem seguia um caminho, não tinha aparência nem de frente nem de trás, aproximou-se da janela e continuou a se aproximar. A velha não tinha como falar, a luz que a cercava se esvaía e uma escuridão profunda rodeou a janela pela qual a idosa observava. A velha já não aguardava por mais nada, seu olhar estava fixo naquela escuridão. Seu olhar parecia com o olhar de alguém que foi cegado e desaparece junto a uma janela envolta pelas trevas. A velha permaneceu sozinha e sua vida se apagou como um pavio prestes a se exaurir. A idosa flutuou em direção à figura que não possuía imagem e sua tristeza se extinguiu para a eternidade. 